\title{
The effects of long-term vigorous endurance exercise on the coronary arteries
}

\section{EXERCISE IS MEDICINE}

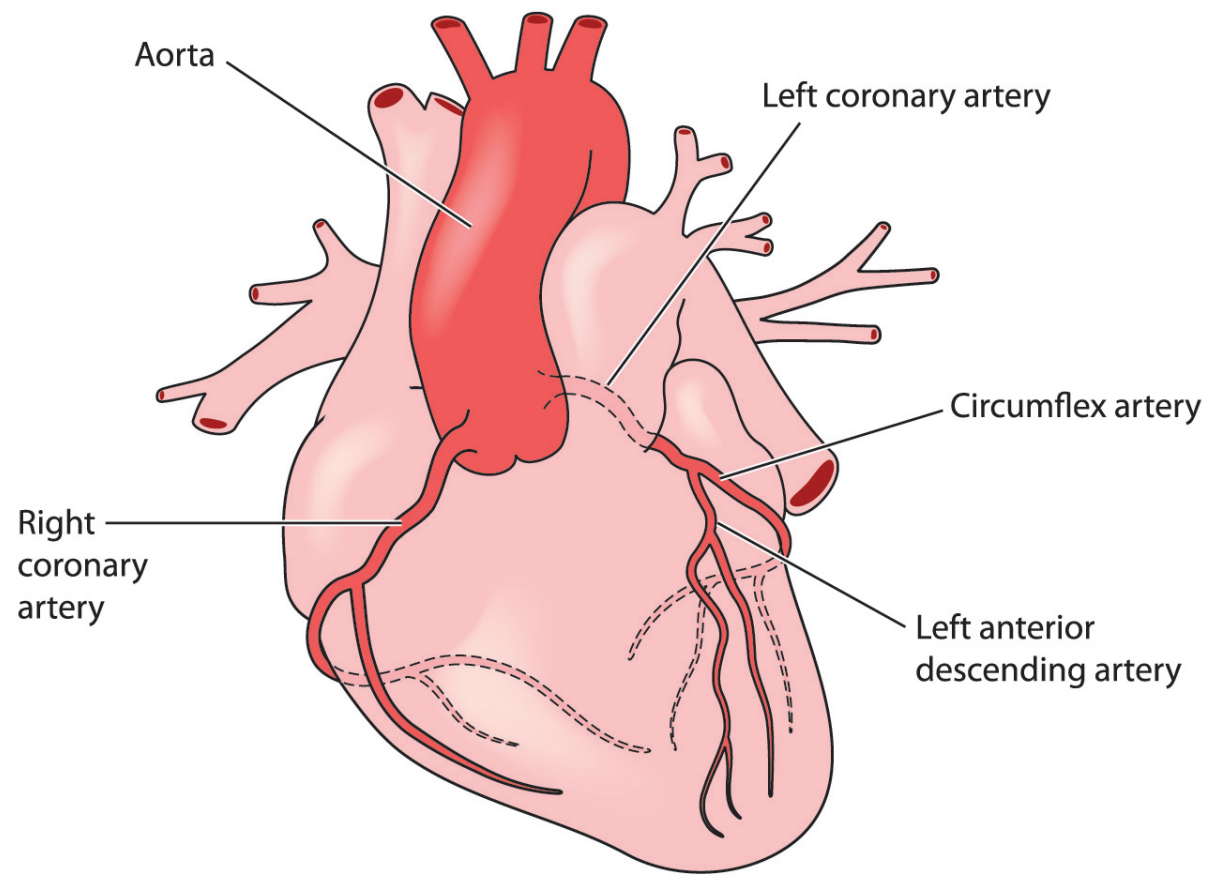

\section{Kissel $\mathrm{CK}^{1}$, Gabus $\mathrm{V}^{2}$, Baggish $\mathrm{AL}^{3}$}

${ }^{1}$ University Heart Centre, Dept. of Cardiology, University Hospital Zurich, Switzerland

${ }^{2}$ Dept. of Cardiology, University Hospital Lausanne, Switzerland

${ }^{3}$ Cardiovascular Performance Program, Massachusetts General Hospital, Boston, MA, USA

\section{Abstract}

Moderate endurance training is known to improve cardiovascular risk factors, and prolongs life expectancy. On the other hand, there has been some discussion whether "too much" exercise might have a contrarious effect by accelerating coronary atherosclerosis. The goal of this review was to evaluate the current literature on the effects of long-term vigorous endurance training on the coronary vasculature. In 
summary, data point to an increased calcium score, and a higher burden of atherosclerotic plaque in male athletes compared to sedentary controls. However, the plaques found in athletes were more prone to be calcified. The pathogenesis and clinical relevance of this athlete coronary artery disease phenotype remains incompletely understood and represents an area of important future work.

\section{Zusammenfassung}

Es ist gut bekannt, dass moderates Ausdauertraining kardiovaskuläre Risikofaktoren verbessert und die Lebenserwartung verlängert. Auf der anderen Seite wird in letzter Zeit diskutiert, ob ein «Zuviel» an Sport möglicherweise gegenteilige Effekte hat und die Entwicklung einer koronaren Atherosklerose gar beschleunigt. Ziel dieses Reviews war, die aktuelle Literatur zu Auswirkungen von langzeitigem, intensiven Ausdauertraining auf die koronaren Gefässe zu untersuchen. Zusammenfassend deuten aktuelle Daten daraufhin, dass männliche Athleten im Vergleich zu sedentären Individuen einen höheren Kalziumscore haben, als auch mehr arteriosklerotische Plaques, welche jedoch häufiger kalzifiziert zu sein scheinen. Die Pathogenese und klinische Relevanz diesen «athletischen Phänotyps» der koronaren Herzerkrankung ist bis dato unklar und stellt eine wichtige Fragestellung für zukünftige Forschung dar. 


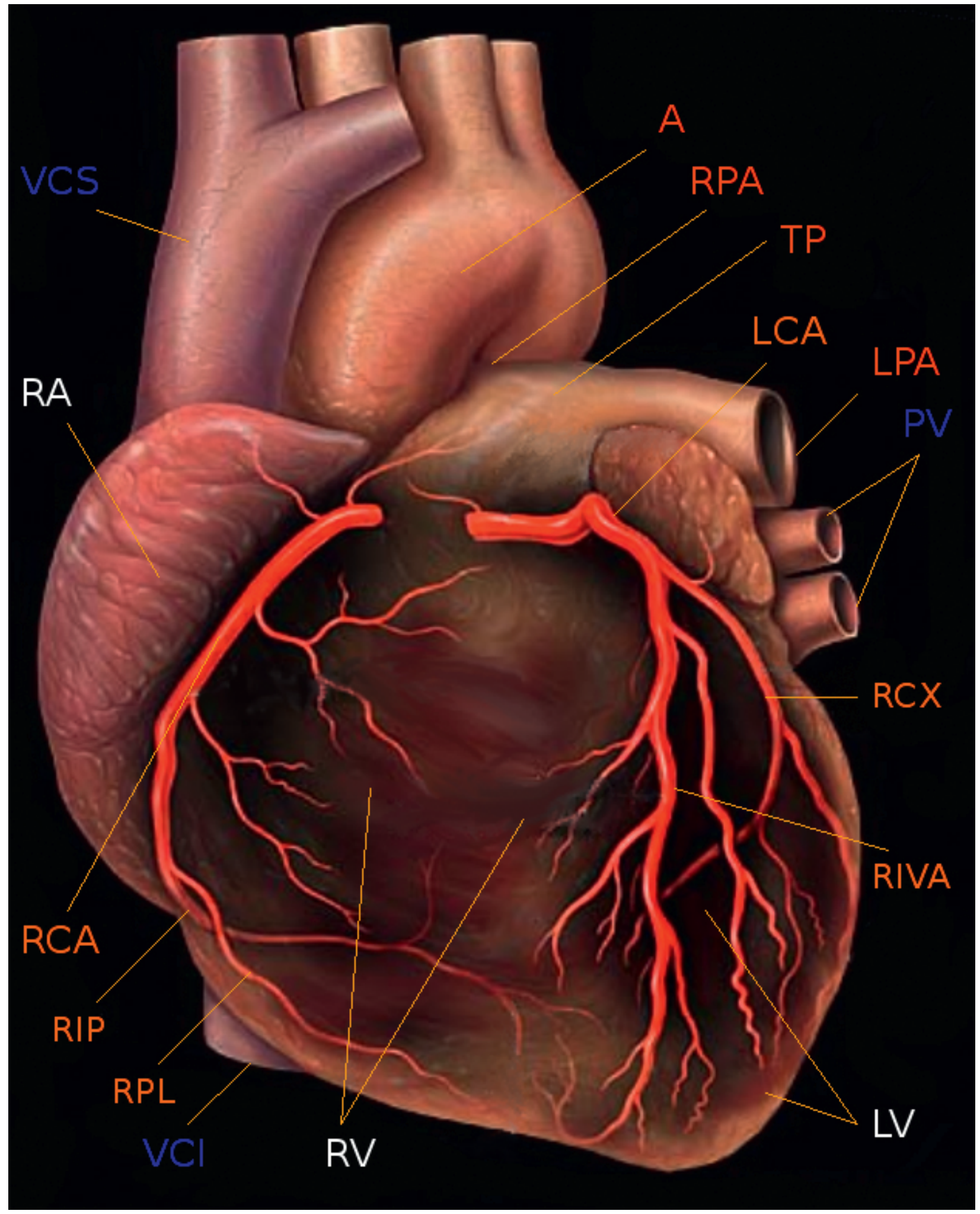

By Patrick J. Lynch (1999), modified by Christian 2003 - Yale University - School of medicine, CC BY 2.5, https://commons.wikimedia.org/w/index.php?curid=2586695 


\section{Introduction}

Moderate intensity aerobic exercise training improves cardiovascular risk factors (CVRF), reduces the risk of incident coronary artery disease (CAD), and increases longevity [1-4]. Consequently, current evidencebased clinical practice guidelines from numerous oversight organizations recommend at least 150 minutes per week of moderate intensity exercise [3,5,6]. While the health impact of exercise at higher intensities remains incompletely understood, available data suggest that people who perform vigorous (i.e. high intensity) physical activity reduce their risk of coronary artery disease [7]. Similar findings have been documented among prior professional tour de France cyclists [8]. Given that CVRF are influenced in a positive manner by exercise training, one would assume that long-term endurance athletes have a lower burden of CAD. This concept has been challenged by recent studies that document significant coronary atherosclerosis among athletes with high level exercise exposure. These observational studies have generated debate about whether intensive long-term endurance training, particularly at exercise doses that far exceed current physical activity recommendations, might actually be harmful. To what degree it is possible to get "too much" exercise, specifically to what degree high levels of exercise may promote rather than protect against $\mathrm{CAD}$, remains an area of active debate. This review was conducted in attempt to bring clarity to this important area of clinical and scientific uncertainty. The following considerations refer to the rapidly expanding population of "masters athletes", defined here as men and women above the age of 35 who engage in endurance exercise training with competitive aspirations.

\section{Exercise and Coronary Artery Health: Historical Considerations}

The notion that routine physical activity confers considerable health benefits is incontrovertible. Pioneering observational studies from the 1950's-60's documented increased longevity, decreased susceptibility to fatal CAD, and favorable CVRF profiles among physically active men [9-11]. During this period of time, the pathologist Thomas Bassler asserted that marathon runners, though perhaps susceptible to sudden death during racing caused by heat stroke and electrolyte imbalances, possessed complete immunity from atherosclerotic CAD [12]. This concept, referred to as the "Bassler Hypothesis", received considerable attention, and was debated both by scientists and general media [13]. A sentinel report published 1977 documented extensive coronary atherosclerosis among accomplished long-distance runners and concluded that "high levels of physical fitness do not guarantee the absence of significant cardiovascular disease" [14]. This small but instructive case series, followed by larger scale confirmatory studies [15-17], definitively disproved the coronary immunity theory and established that obstructive CAD is a possible finding among highly fit people with exertional sudden death. Contemporary case series with credible autopsy data have routinely confirmed this assertion [18].

\section{Mortality Among Masters Endurance Athletes}

Studies examining mortality trends among former elite level endurance athletes have produced consistent results. Specifically, former elite level endurance athletes live longer or at least as long as less active people [19-23]. Extrapolation of these findings to athletes at lower levels of competition including masters recreational and sub-elite competitive athlete should be avoided as genetic selection and unique lifestyle attributes characteristic of elite athletes may in part underlie these observations. However, recent 
epidemiologic data derived from large community based-cohorts confirm associations between increasing doses of habitual physical activity and longevity. Of note, most of the longevity benefit attributable to exercise occurs at relatively low exercise doses (compared to the typically higher levels of exercise performed by competitive masters athletes). For example, a community cohort study from Copenhagen followed 1098 healthy joggers and 3950 healthy non-joggers in an attempt to examine mortality as a function of running dose [24]. Joggers were categorized as light $(n=576)$, moderate $(n=262)$, or strenuous ( $n=40$ ) with the light (HR 0,22; 95\% CI 0,10-0,47) and moderate (HR, 0,66; 95\% CI, 0,32-1,38) jogging groups demonstrating lower mortality compared to sedentary non-joggers. However, the small sub-group of strenuous joggers showed a trend toward increasing mortality [24]. While this surprising finding could be interpreted as indicating a U-shaped curve (i.e. continuous risk reduction with increasing exercise dose up to a point followed by subsequent risk increase with further increasing exercise dose), we caution against this conclusion given the statistically underpowered nature of this sub-group analysis. Similar findings were reported by Lee at al. in a study examining impact of running on mortality in a large cohort ( $\mathrm{n}=$ $55,137)$ comprised of regular runners $(n=13,016)$ and sedentary controls $(n=42,121)$ with runners in the highest "dose" category, here defined as running $\geq 6$ days/week or $\geq 176 \mathrm{~min} /$ week, showing a nonsignificant decrement in exercise-associated health benefits compared to more casual runners [4]. However, one of the largest cohorts examined with respect to physical activity and mortality showed continued mortality benefit through the highest exercise dose measured of 75 MET hours/week when compared to people engaging in negligible leisure time activity [25]. In aggregate, the available data suggest the majority of cardiovascular health benefits attributable to exercise are accrued at relatively low levels of exercise and that former elite level athletes do not appear to pay a "longevity cost" in later life. At present, mortality data examining aging masters athletes, men and women above the age of 35 that engage in high levels of training and competition are lacking.

\section{Coronary Artery Calcification in Masters Endurance Athletes}

The first study to examine coronary calcification among masters athletes in a systematic fashion enrolled 108 male marathon runners who had run more than 5 marathons in the last 3 years [26]. Participants were studied at baseline with cardiac computed tomography (CCT), used here to measure coronary artery calcification (CAC) burden, and cardiac MRI (cMRI) to measure myocardial fibrosis. Athletes, of which more than half were former smokers (51,9\%), were compared to age and Framingham Risk Score matched sedentary controls, and then followed prospectively for a mean duration of 21 months. The prevalence of an Agatston CAC score of greater than 100 was more prevalent in athletes compared to otherwise matched controls and a significant minority of athletes (12\%) demonstrated MR-evidence of myocardial fibrosis, which was associated with a CAC score $\geq 400$. In follow-up, a CAC score $>100$ was associated with an increased CV event rate (4/108). While these data suggested that exercise may lead to coronary calcification, it must be noted that the 4 individuals in this study who experienced clinically significant "events" had a substantial burden of traditional CVRFs, independent of their athletic background. Thus, causal determination of whether marathon running played a causal role in development and/or progression of these men's atherosclerotic CAD could not be established from this study.

A subsequent study from Minneapolis, USA, provided additional relevant data. The authors published 2 papers on 50 male marathon runners, and one on 26 female marathon runners [27-29]. In the first study, CCT, in this case measuring both CAC and non-calcified plaque using CCT-angiography, was used to 
measure the burden of coronary disease among 50 experienced male marathoners. Participant enrollment was confined to men who had completed $\geq 1$ marathon per year for the last 25 year and this group was compared with data derived from 23 sedentary male subjects that underwent CCT-angiography for clinical indications [27]. While attempts were made to match athletes and controls for traditional CVRF, hypertension, dyslipidemia, reduced HDL cholesterol, body mass index (BMI), and diabetes mellitus were higher in the control group while more than half of the marathon runners had a history of prior tobacco use. However, despite the fact that athletes had a lower prevalence of CVRF, they were found to have a higher number of coronary lesions, higher total coronary plaque volume, and a larger volume of both noncalcified and calcified plaque [27]. In a follow-up study, the authors stratified these 50 runners as a function of CAC burden and examined clinical correlates [29]. Runners with any measurable CAC were older, started running and ran their first marathon at an older age, smoked more tobacco, had more traditional CVRF than runners without plaque. The authors therefore concluded that the CAC was not driven by long-term exposure to running but rather well-established traditional cardiovascular risk factors. The third and final study from this group compared 26 female marathon runners (age range $42-82$ years) who ran at least one marathon for the last 10 years to 28 sedentary female controls [28]. This small but important study is the first to examine the issue in female athletes, showed that the runners had a significantly lower coronary lesion prevalence and less total calcified plaque volume compared to sedentary controls. However, controls had a higher prevalence of hypertension, dyslipidemia, history of smoking, and a larger BMI rendering isolation of the effects of running challenging.

\section{From Coronary Artery Calcification to Total Plaque Composition}

Several more recently published studies have further extended our understanding of coronary morphology among masters athletes. The Measuring Athlete's Risk of Cardiovascular Events (MARC) study, based in the Netherlands, used CCT-angiography to examine the coronary atherosclerotic burden in asymptomatic men ( $n=318$ ) over age 45 years who engaged in competitive and/or recreational leisure sports [30]. The authors described a 19\% rate of occult CAD in this population and found that age, BMI, total cholesterol and family history of CAD were independent predictors of CAD. However, the dose of habitual exercise exposure (i.e. the duration, frequency, and intensity of habitual exercise) characterizing this cohort was not provided in detail. In 2017, Aengevaeren et al. further examined the MARC cohort with a goal of examining relationships between $\mathrm{CAD}$ and lifelong exercise volume [31]. In this study, exercise volume was defined by average lifetime exercise exposure as estimated by MET-min per week with division of the cohort into 3 groups (exercise volume groups of $<1000,1000$ to 2000, or $>2000$ MET$\mathrm{min} /$ wk). Furthermore, exercise was classified by intensity as light ( $<3 \mathrm{MET}$ ), moderate (3-6 MET), vigorous (6-9 MET), or very vigorous ( $\geq 9$ MET), and average lifetime hours per week of exercise in the specific intensity ranges were calculated. In sum, 284 white Dutch recreational and competitive athletes from the original study were included. Participants with higher CAC had more traditional CVRFs and very-vigorousintensity habitual exercise (hours per week) was associated with CAC burden. Specifically, athletes performing > 2000 MET-min/wk were more likely to have measurable CAC and the prevalence of any type of coronary plaque was higher in the most active athletes. However, the prevalence of mixed-morphology plaque, the variant most commonly associated with rupture and acute coronary syndromes, was lower in this group while the prevalence of comparatively stable, calcific plaque was higher. Important design elements of this study include the lack of control group and the enrollment of athletes with established 
CAD risk factors. The observation that athletes in the high exercise volume ( $>2000$ MET-min/wk) were more likely than the less active participants to be taking statins and thus presumably more likely to have dyslipidemia raises important questions about the pathogenesis of CAD in this group. To date, the only study that has used an adequate sedentary control group and simultaneously attempted to control sufficiently for traditional CAD risk factors was conducted by Merghani et al. [32]. A total of 152 endurance masters athletes (77\% runners, 23\% cyclists) and 92 matched sedentary controls were extensively evaluated with CCT-angiography and cMRI. Athletic participants were enrolled if they were older than 40 years, ran $\geq 10$ miles or cycled $\geq 30$ miles per week and had done so for $\geq 10$ years, had competed in $\geq 10$ competitive endurance events over a 10-year period, were free of traditional CVRf instead of CAD and lacked an established diagnosis of CAD. Athletes had participated in endurance exercise for an average of 31 $\pm 12,6$ years with a median of 13 marathons and a small proportion were female (30\%). While the majority of athletes and controls were free of CAD (i.e. had not measurable CAC or non-calcified plaque), the prevalence of atherosclerotic plaque was higher in male athletes compared to controls and calcified plaque represented the dominant morphology. Furthermore, a CAC $>70$ th percentile was independently predicted by the number of years of training, but not by weekly exercise dose. There was no significant difference between female athletes and controls but meaningful gender-based conclusions are limited by the statistical power of the observations.

The available data derived from 7 unique cohorts characterizes CAD burden in male masters athletes (total = 993) and female athletes (total $n=276$ ) is summarized in Table 1 . While questions surrounding CAD pathogenesis, specifically the contribution of exercise versus traditional CVRFs and the true clinical relevance of the above summarized findings remain unanswered, several conclusions appear justifiable. First, as initially suggested in the 1970's, no amount of endurance exercise is fully protective against CAD. Second, lifelong exercisers, specifically masters athletes, appear to harbor more CAD than otherwise comparable sedentary counterparts. Third, calcific plaque, the most clinically stable version of CAD, appears to be the dominant plaque morphology in this population. At present, the most critical unanswered question in this field of study is whether the calcific athlete CAD phenotype carries any adverse prognosis or rather represents a relatively benign consequence of lifelong exercise [33]. 


\begin{tabular}{|c|c|c|c|c|c|}
\hline Study, Country & Study Population & Type of Exercise & Tests & Results & Limitations \\
\hline $\begin{array}{l}\text { Hood et al. } \\
\text { Br J Sports Med } \\
1999 \text { [47] } \\
\text { UK }\end{array}$ & $\begin{array}{l}20 \text { veteran ath- } \\
\text { letes, longitudinal } \\
\text { study }\end{array}$ & $\begin{array}{l}\text { Runners } \\
\text { [record holders, } \\
\text { national cham- } \\
\text { pions] }\end{array}$ & 12 years $F / U$, echo & $10 \%$ CAD & $\begin{array}{l}\text { Very small num- } \\
\text { ber, no CTCA, cor- } \\
\text { onary angiogram } \\
\text { only if clinically } \\
\text { indicated }\end{array}$ \\
\hline $\begin{array}{l}\text { Moehlenkamp et } \\
\text { al. EHJ } 2008 \text { [26] } \\
\text { Germany }\end{array}$ & $\begin{array}{l}108 \text { male athletes } \\
>50 a \text {, age/ FRS- } \\
\text { matched Controls } \\
{[50-72 \text { yo] }}\end{array}$ & $\begin{array}{l}\geq 5 \text { marathons in } \\
\text { last } 3 \text { years }\end{array}$ & $\begin{array}{l}\text { CTCA } \\
\text { CMR, lab; } \\
\text { F/U for MI, SCD, } \\
\text { revascularisation } \\
\text { for mean } 21 \\
\text { months }\end{array}$ & $\begin{array}{l}\text { CAC > } 100 \text { more } \\
\text { prevalent in mar- } \\
\text { athon runners; } \\
C A C \geq 400 \text { associ- } \\
\text { ated with CV } \\
\text { events }\end{array}$ & $\begin{array}{l}\text { Not matched for } \\
\text { BMI, BP, HLD, DM, } \\
50 \% \text { former } \\
\text { smokers in ath- } \\
\text { letes }\end{array}$ \\
\hline $\begin{array}{l}\text { Schwartz et al., } \\
\text { Mo Med } 2014 \text { [27] } \\
\text { MN, USA }\end{array}$ & $\begin{array}{l}50 \text { male athletes, } \\
23 \text { sedentary men }\end{array}$ & $\begin{array}{l}\geq 1 \text { marathon/year } \\
\text { for } 25 \text { years }\end{array}$ & CTCA, lab & $\begin{array}{l}\text { increased total } \\
\text { plaque volume, } \\
\text { calcified plaque } \\
\text { volume, and } \\
\text { non-calcified } \\
\text { plaque volume in } \\
\text { athletes }\end{array}$ & $\begin{array}{l}\text { Not matched for } \\
\text { HTN, HLD, BMI, } \\
\text { DM }\end{array}$ \\
\hline $\begin{array}{l}\text { Roberts et al. Med } \\
\text { Sci Sports Exerc } \\
2017 \text { [29] } \\
\text { MN, USA }\end{array}$ & $\begin{array}{l}50 \text { male athletes } \\
\text { Same cohort as } \\
\text { Schwartz et al. } \\
2014 \text {, stratified by } \\
\text { CAC }\end{array}$ & $\begin{array}{l}\geq 1 \text { marathon/year } \\
\text { for } 25 \text { years }\end{array}$ & CTCA, Lab, ECG & $\begin{array}{l}\text { CAC \# of CVRF, } \\
\text { prior tobacco use, } \\
\text { HLD, age, older } \\
\text { age at start of } \\
\text { running; not cor- } \\
\text { related with years } \\
\text { of running }\end{array}$ & $\begin{array}{l}\text { Older age of at } \\
\text { start probably } \\
\text { confounder }\end{array}$ \\
\hline $\begin{array}{l}\text { Roberts et al. Med } \\
\text { Sci Sports Exerc } \\
2017 \text { [28] } \\
\text { MN, USA }\end{array}$ & $\begin{array}{l}26 \text { veteran wom- } \\
\text { en, } 28 \text { sedentary } \\
\text { controls } \\
42-82 \text { yo }\end{array}$ & $\begin{array}{l}\text { Marathon, at least } \\
z 1 \text { year for } 10 \\
\text { years } \\
\text { Propensity } \\
\text { matched seden- } \\
\text { tary controls lagel }\end{array}$ & CTCA, Labs, ECG & $\begin{array}{l}\text { Higher plaque } \\
\text { prevalence in sed- } \\
\text { entary women (14 } \\
\text { vs 5); athletes with } \\
\text { plaque: higher } \\
\text { LDL, more years } \\
\text { of running }\end{array}$ & $\begin{array}{l}\text { Higher prevalence } \\
\text { of risk factors in } \\
\text { controls (HTN, } \\
\text { HLD, smoking } \\
\text { ( } 56 \text { vs } 20 \% \text { ), FHx); } \\
\text { Significantly } \\
\text { heavier }\end{array}$ \\
\hline $\begin{array}{l}\text { Shapero et al. } \\
2016 \text { Sports [34] } \\
\text { MA, USA }\end{array}$ & $\begin{array}{l}391 \text { men, } 200 \\
\text { women, master } \\
\text { athletes > 35a }\end{array}$ & $\begin{array}{l}21+/-13 a \\
\text { competitive en- } \\
\text { durance sport }\end{array}$ & Web based survey & $\begin{array}{l}\text { Prevalence of } \\
\text { CAD } 2.7 \% \text {; prior } \\
\text { smoking and HLD } \\
\text { assoc. with CAD, } \\
\text { not exercise expo- } \\
\text { sure }\end{array}$ & $\begin{array}{l}\text { Survey; reporting } \\
\text { bias, underdiag- } \\
\text { noses, etc. }\end{array}$ \\
\hline $\begin{array}{l}\text { Braber et al., Eur } \\
\text { J Prev Cardiol. } \\
2016 \text { [30] } \\
\text { The Netherlands }\end{array}$ & $\begin{array}{l}318 \text { men, > 45a } \\
\text { MARC study }\end{array}$ & $\begin{array}{l}\text { Competitive and } \\
\text { leisure time } \\
\text { sports activity } \\
\text { (runners, cyclists] }\end{array}$ & CTCA & $\begin{array}{l}19 \% \text { CAD, associ- } \\
\text { ated with more } \\
\text { CVRF }\end{array}$ & $\begin{array}{l}\text { No details of } \\
\text { amount of exer- } \\
\text { cise }\end{array}$ \\
\hline $\begin{array}{l}\text { Aengevaeren et } \\
\text { al., Circulation } \\
2017 \text { [31] } \\
\text { The Netherlands }\end{array}$ & $\begin{array}{l}284 \text { white men } \\
>45 a \\
\text { MARC study }\end{array}$ & $\begin{array}{l}\text { Competitive and } \\
\text { leisure time } \\
\text { sports activity, } \\
\text { [runners, cyclists] }\end{array}$ & $\begin{array}{l}\text { CTCA; Lifelong } \\
\text { exercise history } \\
\text { patterns in MET- } \\
\mathrm{min} / \mathrm{wk}, \mathrm{MET} \text { - } \\
\mathrm{min} / \mathrm{wk} / \text { intensity }\end{array}$ & $\begin{array}{l}\text { Higher prevalence } \\
\text { of CAC in > } \\
2000 \mathrm{MET} / \mathrm{wk} \text {, } \\
\text { more calcified } \\
\text { plaque }\end{array}$ & $\begin{array}{l}\text { CVRF included; no } \\
\text { controls, no } \mathrm{F} / \mathrm{U} \text {; } \\
\text { higher statin use } \\
\text { in most active } \\
\text { group }\end{array}$ \\
\hline $\begin{array}{l}\text { Merghani et al., } \\
\text { Circulation } 2017 \\
\text { [32] } \\
\text { UK }\end{array}$ & $\begin{array}{l}>40 a \text {, no CVRF } \\
\text { Athletes: } 106 \text { men, } \\
46 \text { women; con- } \\
\text { trols: } 54 \text { men, } 38 \\
\text { women }\end{array}$ & $\begin{array}{l}\text { Endurance train- } \\
\text { ing }>10 \mathrm{mi} / \text { wk run- } \\
\text { ning, or }>30 \mathrm{mi} / \mathrm{wk} \\
\text { cycling; }>10 \mathrm{en}- \\
\text { durance races } \\
\text { over } 10 \text { years }\end{array}$ & $\begin{array}{l}\text { ECG, Echo, CTCA, } \\
\text { CMR, CPET, 24h } \\
\text { Holter }\end{array}$ & $\begin{array}{l}\text { Higher plaque } \\
\text { prevalence, more } \\
\text { calcified plaque in } \\
\text { athletes (CAC > } \\
300 \text { ); higher prev- } \\
\text { alence of fibrosis } \\
\text { on MRI }\end{array}$ & $\begin{array}{l}\text { lack of women; } \\
\text { plaque morpholo- } \\
\text { gy only assessed } \\
\text { visually }\end{array}$ \\
\hline
\end{tabular}

$\mathrm{F} / \mathrm{U}=$ follow-up, $\mathrm{CTCA}=$ Computed tomography coronary angiography, $\mathrm{CAC}=$ coronary artery calcification, $\mathrm{MI}=$ myocardial infarction, $\mathrm{BMI}=$ body mass index, $\mathrm{BP}=$ blood pressure, $\mathrm{HLD}=$ hyperlipidemia, $\mathrm{DM}=$ diabetes mellitus, $\mathrm{SCD}=$ sudden cardiac death, $\mathrm{FHx}$ = family history, $\mathrm{HTN}$ = hypertension, wk = week, CPET = cardiopulmonary exercise testing 


\section{Potential Mechanisms Underlying CAD in Masters Athletes}

While the bulk of available data suggest that masters athletes, particularly men, tend to have significant levels of CAC, the etiology of this phenomenon remains incompletely understood and is likely multifactorial. Although routine endurance exercise has positive effects on the traditional CVRF, no amount of exercise can eliminate these issues and they are common among asymptomatic, otherwise healthy masters athletes. The Boston MASTER study examined risk factor profiles among a cohort of community-based endurance masters athletes in Massachusetts, USA [34]. A total of 391 male and 200 female athletes (age $=50 \pm 9$ years) with a competitive endurance sport background spanning $21,3 \pm 12,9$ years including running, cycling, swimming, triathlon, or rowing provided detailed medical information via a web based health and performance survey. Although the prevalence of established CAD was similar in men and women and low overall $(2,7 \%, 16 / 591)$, only approximately one third of the cohort was free of risk factors. A multivariate analysis found no relationship between the number of years of exercise exposure and CAD but rather identified increasing age, the presence of dyslipidemia, and a history of smoking as clinical CAD predictors [34]. An important limitation of this study was the focus on clinically established CAD and the corollary absence of CCT data to determine the burden of sub-clinical pathology. Nonetheless, traditional CAD risk factors are prevalent in masters athletes and almost certainly play a dominant role in the development of disease, particularly when treatment is absent or insufficient. There are additional factors that may contribute either synergistically or in isolation to the emergence and progression of CAD in masters athletes. Hereditary factors including pro-atherosclerotic genetic variants that may manifest as a familial history of premature CAD and that are unlikely to be influenced by exercise may play a role. To date, none of the studies examining CAD have addressed this important potential factor. Ethnicity may be similarly important. For example, Delaney et al. reported that vigorous activity was more protective for African Americans against incident CAC, and being sedentary was even worse for Hispanic-Americans for CAC progression [35]. The relatively homogenous ethnic composition, largely Caucasian, nature of athlete cohorts used in most prior studies precludes meaningful conclusions about the potential impact of ethnicity. Additional possible mechanistic contributors include coronary endothelial injury induced by higher shear stress forces during exercise, pro-atherogenic macronutrient dietary choices, hormonal status, increased oxidative stress, systemic inflammation, exercise-induced hypertension, or other mechanical factors [36-39]. While incompletely understood and not well studied, different forms of endurance exercise with their corollary differences in physiology may potentially have differential impacts on CAD based on preliminary findings suggesting that cyclists appear to have less CAC than runners [40]. The role of inflammation is particularly intriguing as intense exercise is a wellestablished trigger of pro-inflammatory physiology cascades, inflammation appears to play a role in plaque formation [41], and chronic-inflammatory states are known to accelerate atherosclerosis [42]. In a small but instructive study of extremely-high dose exercise which examined coronary health among people running across the USA, elevated levels of C-reactive protein were associated with CAD progression among athletes that had CAD prior to participation [43]. At present, all the above factors remain speculative pending future work. 


\section{Prevention of CAD in Masters Athletes: Clinical Considerations}

Asymptomatic athletes encountered in clinical cardiovascular practice should undergo typical CAD risk assessment as suggested by contemporary clinical guidelines proposed for use in the general population. Pharmacologic and lifestyle-based management of hypertension, dyslipidemia, impaired glucose handling, and tobacco use should be individualized for all masters athletes as part of a thorough wellness plan based on a shared decision making process between the patient and the clinician. We urge caution against the tendency to under-treat traditional CAD risk factors based on the notion that high levels of exercise may exert a therapeutic effect that obviates the need for effective, disease-specific therapeutic options including statins and ACE-inhibitors.

The role of CCT both with and without angiography for further risk stratification in primary prevention in masters athletes has not been firmly established and recommendations are based on opinion rather than data. The European Society of Cardiology recommends calculating a risk-SCORE to assess 10-year CAD event risk (https://www.escardio.org/Education/Practice-Tools/CVD-prevention-toolbox/SCORE-Risk-Charts). The risk-SCORE is derived using a tool that includes all traditional CVRF aside from family CAD history [44]. Athletes found to be at high risk based on this scoring tool should undergo maximal effort-limited exercise testing to screening for obstructive coronary lesions. The recently published European algorithm suggests the use of a CCT-angiogram among high risk athletes only following the finding of pathology (ischemic ECG changes, inducible ventricular arrhythmia, etc.) on exercise testing [45]. In some cases, masters athletes with traditional CAD risk factors may resist treatment recommendations based on false assumptions that they are too healthy to have medical issues. Also, athletes with a strong family history for $\mathrm{CV}$ disease can be quite unsettled about their actual CV risk, and with no other classical risk factors, SCORE tends to underestimate $\mathrm{CV}$ risk since hereditary factors are not taken into account. In such cases and only after a thorough discussion of the risk and benefits, CCT-angiography or perhaps CAC scoring in isolation may be a useful tool to help clinical decision making and risk stratification for the doctor and clinical recommendation acceptance for the patient.

Masters athletes with documented subclinical CAD should be considered for lifestyle counseling and pharmacologic therapy on a case-by-case basis. At the present, the role of aspirin therapy for primary prevention remains unknown and controversial [46]. Exercise restrictions for masters athletes with CAD should be based on the presence of obstructive disease and underlying left ventricular function [45]. Among asymptomatic athletes without obstructive coronary disease and normal left ventricular function, full participation in endurance sport with continued long-term clinical surveillance is appropriate.

\section{Conclusions}

Available data suggest that masters athletes are at risk for the development of CAD. Among asymptomatic masters athletes, the CAD most commonly encountered assumes a calcific non-obstructive morphology. The pathogenesis and clinical relevance of this athlete CAD phenotype remains incompletely understood and represents an area of important future work. Large scale studies comprised of diverse cohorts with respect to age, gender, sport type, and ethnicity coupled with prospective clinical follow-up will be required to address the many unanswered questions in this field. 


\section{Corresponding author}

Christine K. Kissel

University Heart Centre

Dept. of Cardiology

University Hospital Zurich

Rämistrasse 100, 8091 Zürich

Phone: +41-44-2553327

Email: Christine.Kissel@usz.ch

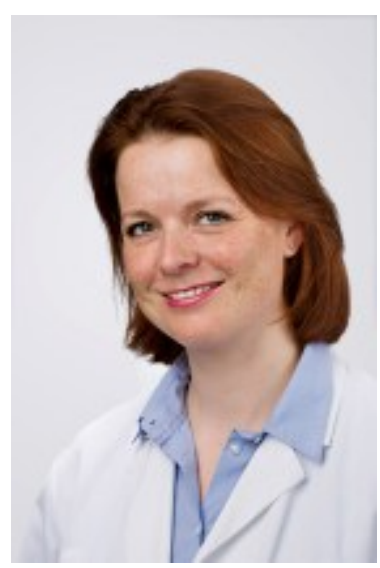

\section{References}

1. Thompson PD, Buchner D, Pina IL, Balady GJ, Williams MA, Marcus BH, et al. Exercise and physical activity in the prevention and treatment of atherosclerotic cardiovascular disease: a statement from the Council on Clinical Cardiology (Subcommittee on Exercise, Rehabilitation, and Prevention) and the Council on Nutrition, Physical Activity, and Metabolism (Subcommittee on Physical Activity). Circulation. 2003;107(24):3109-16.

2. Tanasescu M, Leitzmann MF, Rimm EB, Willett WC, Stampfer MJ, Hu FB. Exercise type and intensity in relation to coronary heart disease in men. JAMA. 2002;288(16):1994-2000.

3. Haskell WL, Lee IM, Pate RR, Powell KE, Blair SN, Franklin BA, et al. Physical activity and public health: updated recommendation for adults from the American College of Sports Medicine and the American Heart Association. Circulation. 2007;116(9):1081-93.

4. Lee DC, Pate RR, Lavie CJ, Sui X, Church TS, Blair SN. Leisure-time running reduces all-cause and cardiovascular mortality risk. J Am Coll Cardiol. 2014;64(5):472-81.

5. Piepoli MF, Hoes AW, Agewall S, Albus C, Brotons C, Catapano AL, et al. 2016 European Guidelines on cardiovascular disease prevention in clinical practice: The Sixth Joint Task Force of the European Society of Cardiology and Other Societies on Cardiovascular Disease Prevention in Clinical Practice (constituted by representatives of 10 societies and by invited experts)Developed with the special contribution of the European Association for Cardiovascular Prevention \& Rehabilitation (EACPR). Eur Heart J. 2016;37(29):2315-81.

6. Arnett DK, Blumenthal RS, Albert MA, Buroker AB, Goldberger ZD, Hahn EJ, et al. 2019 ACC/AHA Guideline on the Primary Prevention of Cardiovascular Disease.0(0):CIR.0000000000000678.

7. Sesso HD, Paffenbarger RS, Jr., Lee IM. Physical activity and coronary heart disease in men: The Harvard Alumni Health Study. Circulation. 2000;102(9):975-80.

8. Sanchis-Gomar F, Olaso-Gonzalez G, Corella D, Gomez-Cabrera MC, Vina J. Increased average longevity among the "Tour de France” cyclists. Int J Sports Med. 2011;32(8):644-7.

9. Morris JN, Heady JA, Raffle PAB, Roberts CG, Parks JW. CORONARY HEART-DISEASE AND PHYSICAL ACTIVITY OF WORK. The Lancet. 1953;262(6796):1111-20.

10. Paffenbarger RS, Gima AS, Laughlin E, Black RA. Characteristics of longshoremen related fatal coronary heart disease and stroke. American journal of public health. 1971;61(7):1362-70.

11. Taylor HL, Klepetar E, Keys A, Parlin W, Blackburn H, Puchner T. Death rates among physically active 
and sedentary employees of the railroad industry. American journal of public health and the nation's health. 1962;52(10):1697-707.

12. Bassler TJ. Marathon Running and Immunity to Heart Disease. Phys Sportsmed. 1975;3(4):77-80.

13. Crossen D. Marathon's Benefit To Heart Is Debated. New York Times. The New York Times. OCT. 16, 1979.

14. Noakes T, Opie L, Beck W, McKechnie J, Benchimol A, Desser K. CORONARY HEART DISEASE IN MARATHON RUNNERS. Annals of the New York Academy of Sciences. 1977;301(1):593-619.

15. Thompson PD, Stern MP, Williams P, Duncan K, Haskell WL, Wood PD. Death During Jogging or Running: A Study of 18 Cases. JAMA. 1979;242(12):1265-7.

16. Thompson PD, Funk EJ, Carleton RA, Sturner WQ. Incidence of death during jogging in Rhode Island from 1975 through 1980. JAMA. 1982;247(18):2535-8.

17. Virmani R, Robinowitz M, McAllister HA, Jr. Nontraumatic death in joggers. A series of 30 patients at autopsy. Am J Med. 1982;72(6):874-82.

18. Kim JH, Malhotra R, Chiampas G, d'Hemecourt P, Troyanos C, Cianca J, et al. Cardiac arrest during long-distance running races. N Engl J Med. 2012;366(2):130-40.

19. Sarna S, Sahi T, Koskenvuo M, Kaprio J. Increased life expectancy of world class male athletes. Medicine \& Science in Sports \& Exercise. 1993;25(2):237-44.

20. Chakravarty EF, Hubert HB, Lingala VB, Fries JF. Reduced Disability and Mortality Among Aging Runners: A 21-Year Longitudinal Study. JAMA Internal Medicine. 2008;168(15):1638-46.

21. Farahmand BY, Ahlbom A, Ekblom Ö, Ekblom B, Hållmarker U, Aronson D, et al. Mortality amongst participants in Vasaloppet: a classical long-distance ski race in Sweden. Journal of Internal Medicine. 2003;253(3):276-83.

22. Clarke PM, Walter SJ, Hayen A, Mallon WJ, Heijmans J, Studdert DM. Survival of the fittest: retrospective cohort study of the longevity of Olympic medallists in the modern era. BMJ. 2012;345:e8308.

23. Marijon E, Tafflet M, Antero-Jacquemin J, El Helou N, Berthelot G, Celermajer DS, et al. Mortality of French participants in the Tour de France (1947-2012). European Heart Journal. 2013;34(40):3145-50.

24. Schnohr P, O'Keefe JH, Marott JL, Lange P, Jensen GB. Dose of jogging and long-term mortality: the Copenhagen City Heart Study. J Am Coll Cardiol. 2015;65(5):411-9.

25. Arem H, Moore SC, Patel A, Hartge P, Berrington de Gonzalez A, Visvanathan K, et al. Leisure time physical activity and mortality: a detailed pooled analysis of the dose-response relationship. JAMA internal medicine. 2015;175(6):959-67.

26. Mohlenkamp S, Lehmann N, Breuckmann F, Brocker-Preuss M, Nassenstein K, Halle M, et al. Running: the risk of coronary events: Prevalence and prognostic relevance of coronary atherosclerosis in marathon runners. Eur Heart J. 2008;29(15):1903-10.

27. Schwartz RS KS, Schwartz JG, Wickstrom KK, Peichel G, Garberich RF, Lesser JR, Oesterle SN, Knickelbine T, Harris KM, Duval S, Roberts WO, O’Keefe JH. Increased Coronary Artery Plaque Volume Among Male Marathon Runners. Mo Med. 2014;111(85).

28. Roberts WO, Schwartz RS, Kraus SM, Schwartz JG, Peichel G, Garberich RF, et al. Long-Term Marathon Running Is Associated with Low Coronary Plaque Formation in Women. Med Sci Sports Exerc. 2017;49(4):641-5.

29. Roberts WO, Schwartz RS, Garberich RF, Carlson S, Knickelbine T, Schwartz JG, et al. Fifty Men, 3510 Marathons, Cardiac Risk Factors, and Coronary Artery Calcium Scores. Med Sci Sports Exerc. 2017.

30. Braber TL, Mosterd A, Prakken NH, Rienks R, Nathoe HM, Mali WP, et al. Occult coronary artery disease in middle-aged sportsmen with a low cardiovascular risk score: The Measuring Athlete's Risk of Cardiovascular Events (MARC) study. Eur J Prev Cardiol. 2016;23 (15):1677-84.

31. Aengevaeren VL, Mosterd A, Braber TL, Prakken NHJ, Doevendans PA, Grobbee DE, et al. Relationship Between Lifelong Exercise Volume and Coronary Atherosclerosis in Athletes. Circulation. 2017; 
136(2):138-48.

32. Merghani A, Maestrini V, Rosmini S, Cox AT, Dhutia H, Bastiaenan R, et al. Prevalence of Subclinical Coronary Artery Disease in Masters Endurance Athletes With a Low Atherosclerotic Risk Profile. Circulation. 2017;136(2):126-37.

33. Baggish AL, Levine BD. Coronary Artery Calcification Among Endurance Athletes. Circulation. 2017;136(2):149-51.

34. Shapero K, Deluca J, Contursi M, Wasfy M, Weiner RB, Lewis GD, et al. Cardiovascular Risk and Disease Among Masters Endurance Athletes: Insights from the Boston MASTER (Masters Athletes Survey To Evaluate Risk) Initiative. Sports Med Open. 2016;2:29.

35. Delaney JA, Jensky NE, Criqui MH, Whitt-Glover MC, Lima JA, Allison MA. The association between physical activity and both incident coronary artery calcification and ankle brachial index progression: the multi-ethnic study of atherosclerosis. Atherosclerosis. 2013;230(2):278-83.

36. Goel R, Majeed F, Vogel R, Corretti MC, Weir M, Mangano C, et al. Exercise-induced hypertension, endothelial dysfunction, and coronary artery disease in a marathon runner. Am J Cardiol. 2007;99(5):743-4.

37. Vollaard NB, Shearman JP, Cooper CE. Exercise-induced oxidative stress:myths, realities and physiological relevance. Sports Med. 2005;35(12):1045-62.

38. Kojda G, Hambrecht R. Molecular mechanisms of vascular adaptations to exercise. Physical activity as an effective antioxidant therapy? Cardiovasc Res. 2005;67(2):187-97.

39. Powers SK, Radak Z, Ji LL. Exercise-induced oxidative stress: past, present and future. 2016;594(18):5081-92.

40. Aengevaeren VL, Mosterd A, Sharma S, Braber TL, Thompson PD, Velthuis BK, et al. Coronary Atherosclerosis in Athletes: Exploring the Role of Sporting Discipline. JACC: Cardiovascular Imaging. 2019.

41. Libby P, Theroux P. Pathophysiology of Coronary Artery Disease. 2005;111(25):3481-8.

42. Mason JC, Libby P. Cardiovascular disease in patients with chronic inflammation: mechanisms underlying premature cardiovascular events in rheumatologic conditions. European heart journal. 2015;36(8):482-9c.

43. Lin J, DeLuca JR, Lu MT, Ruehm SG, Dudum R, Choi B, et al. Extreme Endurance Exercise and Progressive Coronary Artery Disease. 2017;70(2):293-5.

44. Piepoli MF, Hoes AW, Agewall S, Albus C, Brotons C, Catapano AL, et al. 2016 European Guidelines on cardiovascular disease prevention in clinical practice: The Sixth Joint Task Force of the European Society of Cardiology and Other Societies on Cardiovascular Disease Prevention in Clinical Practice (constituted by representatives of 10 societies and by invited experts)Developed with the special contribution of the European Association for Cardiovascular Prevention \& Rehabilitation (EACPR). Eur Heart J. 2016;37(29):2315-81.

45. Borjesson M, Dellborg M, Niebauer J, LaGerche A, Schmied C, Solberg EE, et al. Recommendations for participation in leisure time or competitive sports in athletes-patients with coronary artery disease: a position statement from the Sports Cardiology Section of the European Association of Preventive Cardiology (EAPC). European Heart Journal. 2018;40(1):13-8.

46. Chow BJW, Small G, Yam Y, Chen L, McPherson R, Achenbach S, et al. Prognostic and Therapeutic Implications of Statin and Aspirin Therapy in Individuals With Nonobstructive Coronary Artery Disease. 2015;35(4):981-9.

47. Hood S, Northcote RJ. Cardiac assessment of veteran endurance athletes: a 12 year follow up study. $\mathrm{Br}$ J Sports Med. 1999;33(4):239-43. 


\section{CALCIFICATION/ SCLEROSIS}

